\title{
REVIEW
}

\section{Insights into calcium-sensing receptor trafficking and biased signalling by studies of calcium homeostasis}

\author{
Caroline M Gorvin'1,2 \\ IInstitute of Metabolism and Systems Research (IMSR), University of Birmingham, Birmingham, UK \\ ${ }^{2}$ Centre for Endocrinology, Diabetes and Metabolism (CEDAM), Birmingham Health Partners, Birmingham, UK \\ Correspondence should be addressed to C M Gorvin: C.Gorvin@bham.ac.uk
}

\begin{abstract}
The calcium-sensing receptor (CASR) is a class C G-protein-coupled receptor (GPCR) that detects extracellular calcium concentrations, and modulates parathyroid hormone secretion and urinary calcium excretion to maintain calcium homeostasis. The CASR utilises multiple heterotrimeric G-proteins to mediate signalling effects including activation of intracellular calcium release; mitogen-activated protein kinase (MAPK) pathways; membrane ruffling; and inhibition of CAMP production. By studying germline mutations in the CASR and proteins within its signalling pathway that cause hyper- and hypocalcaemic disorders, novel mechanisms governing GPCR signalling and trafficking have been elucidated. This review focusses on two recently described pathways that provide novel insights into CASR signalling and trafficking mechanisms. The first, identified by studying a CASR gain-of-function mutation that causes autosomal dominant hypocalcaemia $(A D H)$, demonstrated a structural motif located between the third transmembrane domain and the second extracellular loop of the CASR that mediates biased signalling by activating a novel $\beta$-arrestin-mediated G-protein-independent pathway. The second, in which the mechanism by which adaptor protein-2 $\sigma$-subunit (AP2 $\sigma$ ) mutations cause familial hypocalciuric hypercalcaemia (FHH) was investigated, demonstrated that AP2 $\sigma$ mutations impair CASR internalisation and reduce multiple CASR-mediated signalling pathways. Furthermore, these studies showed that the CASR can signal from the cell surface using multiple G-protein pathways, whilst sustained signalling is mediated only by the $\mathrm{G}_{\mathrm{q} / 11}$ pathway. Thus, studies of FHH- and ADHassociated mutations have revealed novel steps by which CASR mediates signalling and compartmental bias, and these pathways could provide new targets for therapies for patients with calcaemic disorders.
\end{abstract}

Journal of Molecular Endocrinology (2018) 61, R1-R12

\section{Introduction to the CASR}

Extracellular calcium $\left(\mathrm{Ca}^{2+}{ }_{\mathrm{e}}\right)$ is required for diverse biological functions ranging from blood coagulation, mineralisation of bone matrix, muscle contraction and hormone secretion (Brown 1991). Thus, calcium concentrations within the blood are tightly regulated. The parathyroid gland plays an essential role in calcium

\section{Key Words}

- calcium-sensing receptor

- adaptor protein-2

- familial hypocalciuric hypercalcaemia

- autosomal dominant hypocalcaemia

- biased signalling 
homeostasis by detecting $\mathrm{Ca}^{2+}{ }_{\mathrm{e}}$ in the blood, and in response to hypocalcaemia, secretes the parathyroid hormone (PTH) to normalize serum calcium concentrations. PTH achieves this by: enhancing bone resorption; activating calcium reabsorption at the kidneys; and stimulating the synthesis of 1,25-dihydroxyvitamin $\mathrm{D}_{3}$, which mobilises intestinal calcium absorption (Fig. 1A) (Riccardi \& Brown 2010). The net effect of these three pathways is to increase $\mathrm{Ca}^{2+}{ }_{\mathrm{e}}$, which provides feedback inhibition to the parathyroid gland, to suppress PTH secretion (Conigrave \& Ward 2013). The parathyroid is able to detect $\mathrm{Ca}^{2+}{ }_{\mathrm{e}}$ concentrations in the blood using the cellsurface-expressed calcium-sensing receptor (CASR), a class C G-protein-coupled receptor (GPCR), for which $\mathrm{Ca}^{2+}$ is the major ligand (Riccardi \& Brown 2010, Conigrave \& Ward 2013).

The CASR is a 1078-amino acid protein that exists at cell surfaces as a disulphide-linked homodimer (Ward et al. 1998), although it is capable of forming heterodimers (Gama et al. 2001, Chang et al. 2007). The CASR has a large extracellular domain, which was recently crystallized by two independent laboratories, and consists of a bilobed venus flytrap ligand binding domain (VFTD) and a cysteine-rich domain (CRD) (Geng et al. 2016, Zhang et al. 2016) (Fig. 1B). $\mathrm{Ca}^{2+}{ }_{\mathrm{e}}$ binds between the two lobes (lobe 1 and lobe 2) of the VFTD, which initiates a conformational change, facilitating lobe 2-lobe 2 dimerisation and allowing the CRDs to interact (Geng et al. 2016, Zhang et al. 2016). These conformational changes are predicted to re-orientate the seven-transmembrane (TM) domain (Geng et al. 2016), and consequently activate the associated G-proteins and initiate signal transduction (Standfuss et al. 2011). The CASR has been reported to couple to multiple G-protein subtypes, but predominantly signals by: the $\mathrm{G}_{\mathrm{i} / \mathrm{o}}$ pathway, to suppress cAMP and activate mitogen-activated protein kinase (MAPK) cascades (Kifor et al. 2001, Thomsen et al. 2012); the $\mathrm{G}_{\mathrm{q} / 11}$-phospholipase C (PLC)-mediated pathway, to generate inositol 1,4,5-trisphosphate $\left(\mathrm{IP}_{3}\right)$ and diacylglycerol, that activate intracellular calcium $\left(\mathrm{Ca}^{2+}{ }_{\mathrm{i}}\right)$ mobilisations (Hofer \& Brown 2003) and MAPK pathways, respectively. The CASR can also couple to a G-protein-independent mechanism involving $\beta$-arrestin proteins to also activate MAPK signalling (Thomsen et al. 2012) (Fig. 2).

\section{Human disorders of the CASR provide insights into receptor signalling mechanisms}

The importance of the CASR in the regulation of $\mathrm{Ca}^{2+}{ }_{\mathrm{e}}$ is highlighted in patients with germline mutations of the receptor that have disorders of calcium homeostasis. Heterozygous loss-of-function mutations in the CASR lead to the autosomal dominant condition familial hypocalciuric hypercalcaemia (FHH) (Pollak et al. 1993), which is characterised by lifelong mild-to-moderate hypercalcaemia, normal or mildly raised serum PTH levels and low urinary calcium excretion (Firek et al. 1991, Marx 2015). FHH is considered to be a benign disorder as most patients are asymptomatic, but it can be associated with chondrocalcinosis and pancreatitis in some cases (Pearce et al. 1996a, Volpe et al. 2009, Hannan \& Thakker 2013).
A

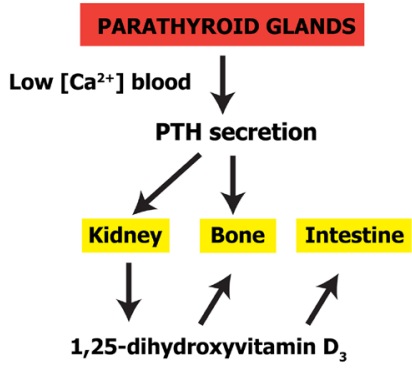

B

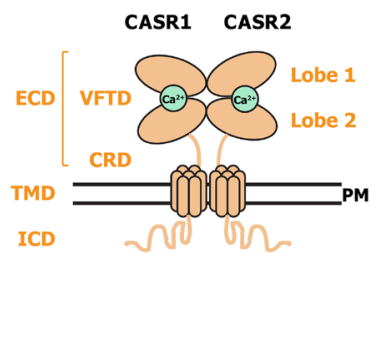

Figure 1

Regulation of extracellular calcium at the parathyroid glands. (A) Schematic illustrating how the parathyroid glands respond to changes in extracellular calcium concentrations $\left[\mathrm{Ca}^{2+}{ }_{\mathrm{e}}\right]$ in the blood. In the presence of low $\left[\mathrm{Ca}^{2+}{ }_{\mathrm{e}}\right]$ in the blood, the parathyroid glands secrete parathyroid hormone (PTH). PTH binds to PTH receptors at the kidney, resulting in calcium reabsorption, and activation of 1,25-dihydroxyvitamin $\mathrm{D}_{3}$; which in turn acts upon bone to mediate calcium release, and the intestine to activate calcium resorption. PTH also acts directly on bone to activate calcium release. The tissue-specific effects on calcium are shown in the hatched box with an arrow to indicate that these are increased by low [Ca2+] in the blood. (B) Schematic of the homodimeric calcium-sensing receptor (CASR) showing the two protomers (CASR1 and CASR2) within the plasma membrane (PM). The CASR is expressed highly at the parathyroid gland and its major function is to detect $\left[\mathrm{Ca}^{2+}{ }_{\mathrm{e}}\right]$ and regulate PTH secretion accordingly. The CASR has a large extracellular domain (ECD) comprising the venus flytrap domain (VFTD) that contains two lobes (lobe 1 and lobe 2), and a cysteine-rich domain (CRD). The CRD connects the ECD to the 7-transmembrane domains (TMD), and the CASR has a long cytoplasmic intracellular domain (ICD). lonised calcium binds between the two lobes of the VFTD. In the presence of high calcium, the CASR is activated, leading to changes in its signal transduction and reduced PTH secretion. 


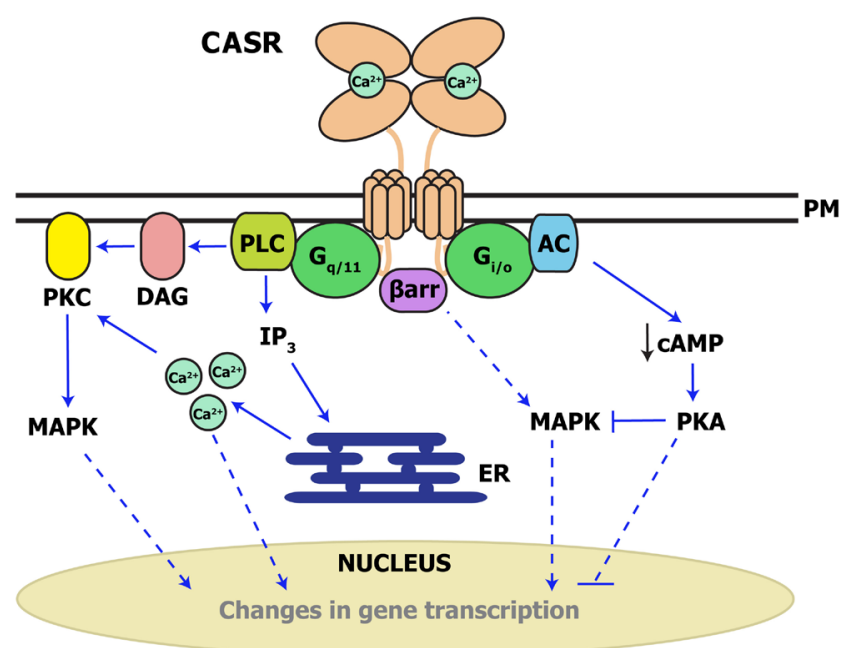

Figure 2

Major signalling pathways of the calcium-sensing receptor (CASR). Schematic diagram of the calcium-bound homodimeric CASR and its major signalling pathways. The CASR is expressed at the plasma membrane (PM) where its function is to detect $\left[\mathrm{Ca}^{2+}{ }_{\mathrm{e}}\right]$ in the blood. The CASR activates two major signalling pathways: $G_{q / 11}$ and $G_{i / o}$. Activation of the $G_{q / 11}$ pathway leads to stimulation of its major effector protein phospholipase C (PLC), which hydrolyses phosphatidylinositol 4,5-bisphosphate $\left(\mathrm{PIP}_{2}\right)$ to the second messengers diacylglycerol (DAG) and inositol trisphosphate $\left(\mathrm{IP}_{3}\right)$. DAG activates protein kinase $\mathrm{C}(\mathrm{PKC})$ and the mitogen-activated protein kinase (MAPK) signalling pathway. $\mathrm{IP}_{3}$ binds to $\mathrm{IP}_{3}$ receptors at the $\mathrm{ER}$, which mobilise intracellular calcium $\left(\mathrm{Ca}^{2+}\right)$ release into the cytoplasm. This increase in $\mathrm{Ca}^{2+}{ }_{\mathrm{i}}$ can further activate MAPK signalling. The CASR also activates $\mathrm{G}_{\mathrm{i} / \mathrm{o}}$ signalling pathways, which inhibits adenylate cyclase $(A C)$, resulting in reductions in CAMP and protein kinase A (PKA) activity. This reduction in PKA relieves the inhibition on MAPK signalling and therefore provides another activation pathway for MAPK signalling. The net effect of all these signalling pathways is a change in gene transcription.

Homozygous and compound heterozygous loss-offunction mutations of the CASR are the common cause of neonatal severe hyperparathyroidism (NSHPT), which is characterised by marked elevations in serum calcium and $\mathrm{PTH}$, failure to thrive and hyperparathyroid bone disease (Pollak et al. 1993, Chattopadhyay \& Brown 2006, Hannan \& Thakker 2013). On occasion, heterozygous CASR mutations may lead to an NSHPT-like phenotype, and this is largely due to the dominant-negative nature of the mutant receptor on the wild-type (WT) CASR in these cases (Pearce et al. 1995, Obermannova et al. 2009).

Gain-of-function mutations of the CASR cause autosomal dominant hypocalcaemia (ADH) characterised by mild-to-moderate hypocalcaemia and inappropriately low or normal PTH concentrations (Pearce et al. 1996b, Hannan \& Thakker 2013). Up to 50\% of patients present with hypocalcaemic symptoms of paraesthesia, carpopedal spasms, seizures and ectopic calcification of the kidneys and basal ganglia (Pearce et al. 1996b,
Hannan \& Thakker 2013). Some patients with gainof-function mutations in CASR may have Bartter syndrome type 5 , which is characterised by renal salt wasting, hypokalaemia, hyperreninaemia and hyperaldosteronaemia (Vargas-Poussou et al. 2002, Watanabe et al. 2002).

\section{Biased signalling of the CASR}

Functional studies in HEK293 cells have demonstrated that disease-causing mutations may influence CASR signalling responses in a biased manner (Leach et al. 2012). Despite the capability of the CASR to signal via multiple signalling pathways, in vitro studies in HEK293 cells have shown that it preferentially couples to the $\mathrm{Ca}^{2+}{ }_{\mathrm{i}}$ signalling pathway (Leach et al. 2012). In contrast, disease-causing CASR mutants have been shown to switch this preferential signalling, with some FHH1-causing mutations signalling equally via the $\mathrm{Ca}^{2+}{ }_{\mathrm{i}}$ and MAPK pathways, or predominantly via MAPK pathways, while many ADH1-associated mutants couple more strongly to $\mathrm{Ca}^{2+}{ }_{\mathrm{i}}$ (Leach et al. 2012). Furthermore, studies of positive and negative allosteric CASR modulating compounds, revealed they too can mediate a biased signalling response, with both classes of drugs influencing $\mathrm{Ca}^{2+}{ }_{\mathrm{i}}$ to a greater extent than ERK1/2 phosphorylation (Leach et al. 2013). Thus, these findings established that agonist-induced CASR signalling may occur in a biased manner, although the GPCR structural motifs mediating ligand-dependent bias were not described.

\section{Novel insights into mechanisms by which CASR can mediate signalling bias}

Recently, a novel ADH1-associated CASR mutation, Arg680Gly, has provided some insights into the molecular mechanisms mediating signalling bias (Gorvin et al. 2018a). In vitro analyses showed that $\mathrm{Ca}^{2+}{ }_{\mathrm{i}}$ signalling in cells expressing the Arg680Gly mutation was not different to that observed in WT cells, in contrast to previously reported ADH1-associated CASR mutants (Gorvin et al. 2018a). However, the Arg680Gly mutation did enhance MAPK signalling (Gorvin et al. 2018a). Furthermore, this type of signalling bias, in which an ADH1 mutation enhances MAPK signalling but does not affect $\mathrm{Ca}^{2+}{ }_{i}$, has not previously been described and provided an opportunity to explore the role of the Arg680 residue in CASR structurefunction. As MAPK acts as a convergence pathway for multiple CASR signalling pathways (Fig. 2), each was investigated using a single reporter assay measuring 
luciferase upstream of a serum-response element (SRE), which acts as a measure for MAPK-mediated transcription (Gorvin et al. 2017b). By applying compounds that specifically block the $\mathrm{G}_{\mathrm{q} / 11}$ ((YM-245890 and UBO-QIC), the $\mathrm{G}_{\mathrm{i} / \mathrm{o}}$ (pertussis toxin) or the $\beta$-arrestin ( $\beta$-arrestin-1 and $\beta$-arrestin- 2 targeting siRNA) pathways, it was shown that the Arg680Gly mutation enhanced MAPK signalling by a $\beta$-arrestin1/2-mediated pathway (Takasaki et al. 2004, Schrage et al. 2015, Gorvin et al. 2018a).

The structural location of the mutant residue within the CASR transmembrane domain (TMD) region provides some insights into the likely mechanism mediating this bias. Homology modelling of the CASR TMD, based upon the structure of the closely related human metabotropic glutamate receptor 1 (mGluR1) (Hu et al. 2005, Gorvin et al. 2018a), predicts that the Arg680 residue lies at the extracellular side of TM3, and that the residue forms saltbridge connections with the side chain of adjacent residues in extracellular loop 2 (ECL2) (Glu767) or TM7 (Glu837) (Fig. 3). Such connections between residues within TMDs or with ECLs of GPCRs are known to be important in receptor activity. For example, TM3 and TM6 of the $\beta 2 \mathrm{AR}$ form ionic interactions which lock the receptor in an inactive state, and conformational changes within these helices govern G-protein coupling at the cytoplasmic face of the receptor (Ballesteros et al. 2001, Rasmussen et al. 2007). Furthermore, disruption of a salt-bridge in $\beta 2$-AR allows lateral displacement of TM3 away from TM4 and TM5, facilitating $\beta$-arrestin binding (Shukla et al. 2014), and it was therefore hypothesised that the CASR Arg680Gly mutation may break a salt-bridge between TM3 and ECL 2 or TM7, allowing $\beta$-arrestin to bind more readily at the CASR cytoplasmic face (Gorvin et al. 2018a). The importance of the Arg680, Glu767 and Glu837 residues in the CASR has previously been recognised. Mutation of Glu767 and Glu837 has been shown to increase signalling by the CASR (Hu et al. 2002, 2005, 2006, Uckun-Kitapci et al. 2005), and previous structural homology models that investigated the binding of allosteric modulator drugs with the CASR demonstrated that the three residues form critical contacts for drug binding (Miedlich et al. 2004, Petrel et al. 2004), indicating their importance in CASR structure-function. To investigate the hypothesis that a salt-bridge is disrupted by mutation of Arg680, a series of mutations were engineered at the Arg680, Glu767 and Glu837 residues. First, Glu767 and Glu837 were mutated to Arg residues, to introduce unfavourable electrostatic interactions. Under these conditions, the Glu767Arg engineered mutant was shown to enhance MAPK activity in a similar way to the Arg680Gly ADH1 mutant,
A
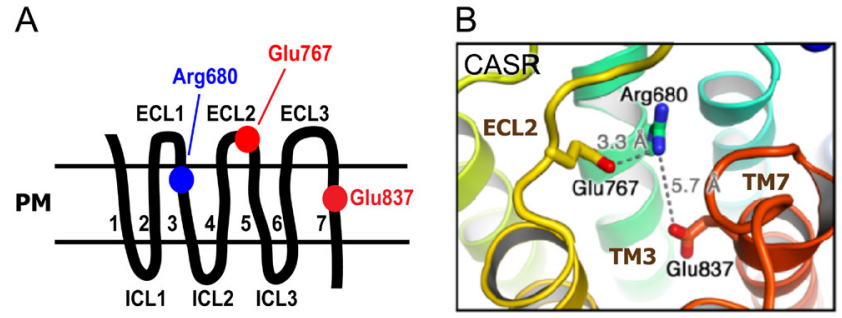

Figure 3

Disruption of an Arg680-Glu767 salt-bridge within CASR mediates signalling bias by activation of a G-protein independent, $\beta$-arrestin pathway. (A) Schematic diagram of a CASR monomer at the plasma membrane (PM) showing the seven-transmembrane domains (TM1-7) with extracellular loops 1-3 (ECL1-3) and intracellular loops 1-3 (ICL1-3). Arg680 is located at the extracellular end of TM3 and is predicted to form a salt-bridge with either a Glu767 residue on ECL2 or a Glu837 residue on TM7. (B) Homology model of the CASR TM3, TM7 and ECL2 region, reproduced with permission from (Gorvin et al. 2018a). The homology model is based on the published structure of mGluR1 (Wu et al. 2014). The Arg680 residue is shown projecting from TM3 and is predicted to form a salt-bridge with Glu767 on ECL2. The Glu837 residue on TM7 lies at a $5.7 \AA$ distance from the Arg680 residue, and therefore formation of a salt-bridge between Arg680 and Glu837 is less likely, but was tested as the homology model may not reflect the true state of CASR.

a response that was also $\beta$-arrestin sensitive (Gorvin et al. 2018a). In contrast, responses in cells expressing the CASR Glu837Arg engineered mutant were similar to those in cells expressing WT CASR (Gorvin et al. 2018a). To confirm that a salt-bridge is required between residues 680 and 767 in the CASR, a double mutant was generated by mutating the Glu767Arg mutant receptor with an additional missense mutation of Arg680 to Glu680. This should allow the salt-bridge between the two residues to reform. Indeed, in this double mutant (Glu680-Arg767) CASR, MAPK signalling was restored to levels similar to those seen in WT cells (Gorvin et al. 2018a).

Thus, these studies have revealed some of the important structural motifs of CASR that mediate signalling bias, and discovery of this novel $\beta$-arrestinspecific pathway may help facilitate the development of targeted therapeutics for CASR. Furthermore, it demonstrates the importance of investigating multiple signalling outputs downstream of CASR, to ensure that potentially disease-causing mutations are not classified as benign polymorphisms (Gorvin et al. 2018a).

\section{Insights from human genetic mutations in components of the CASR signalling pathway}

Both FHH and ADH are genetically heterozygous conditions with mutations in the CASR accounting for approximately $65 \%$ and $70 \%$ of cases, respectively (Hannan et al. 2012, Nesbit et al. 2013a). Two further 
genetically distinct forms of $\mathrm{FHH}$, and one further distinct form of $\mathrm{ADH}$, have been described (Mannstadt et al. 2013, Nesbit et al. 2013a,b). Heterozygous loss- and gain-of-function germline mutations in the $\alpha$-subunit of G-protein $11\left(\mathrm{G} \alpha_{11}\right)$, a component of the CASR signalling pathway, give rise to FHH type-2 (FHH2) and ADH type-2 (ADH2), respectively (Mannstadt et al. 2013, Nesbit et al. 2013a). Only four FHH2 and six ADH2 mutations have been described to date, and therefore these mutations account for only a small number of cases of these disorders (Mannstadt et al. 2013, Nesbit et al. 2013a, Li et al. 2014, Gorvin et al. 2016, 2017a, Piret et al. 2016). FHH type-3 (FHH3) is due to mutations in the sigma subunit of the adaptor protein-2 (AP2 $\sigma)$, which plays a fundamental role in clathrin-mediated endocytosis of transmembrane proteins, such as GPCRs (Nesbit et al. 2013b). The AP2o protein is ubiquitously expressed, and clathrin-mediated endocytosis is a critical cellular process; however, FHH is a largely benign condition, and the phenotypes observed in FHH3 patients are largely CASR-specific. Thus, by studying the AP2 $\sigma$ mutations identified in FHH3, which have been described in a single residue (Nesbit et al. 2013b, Hannan et al. 2015), novel insights into the trafficking and signalling mechanisms of CASR have been elucidated, and indicate an important interplay between these two processes (Gorvin et al. 2018b).

\section{Trafficking of the CASR}

The cell surface expression of the CASR is important for detecting extracellular ligand and signalling by the receptor, and therefore the plasma membrane expression of CASR is carefully regulated. This involves multiple pathways including: receptor synthesis and secretion, trafficking to the plasma membrane and removal of the CASR from the cell surface by endocytosis.

\section{Regulation of cell surface expression by functional desensitisation}

In contrast to most GPCRs, which undergo agonistdependent desensitisation by phosphorylation and/or by $\beta$-arrestin proteins, functional desensitisation appears to have only a minimal impact on CASR expression, and there are inconsistencies between findings in these studies (Bouschet et al. 2005, Pi et al. 2005, Lorenz et al. 2007, Thomsen et al. 2012). Initial studies of the CASR showed that several proteins desensitise the receptor. These include: PKC, which phosphorylates the receptor following activation of signalling pathways and recruits $\beta$-arrestin; G-protein regulatory kinase (GRK) 2, which binds to $G \alpha_{\mathrm{q}}$ and inhibits its signalling; and GRK4, which phosphorylates CASR to facilitate desensitisation (Pi et al. 2005, Lorenz et al. 2007). Furthermore, GRKs and $\beta$-arrestin have independent functions as combined treatment of cells with these proteins enhances desensitisation (Lorenz et al. 2007). The traditional view of GPCR desensitisation and internalisation was one in which the receptor is phosphorylated and $\beta$-arrestin recruited, followed by internalisation of the receptor by clathrin-mediated endocytosis, which is facilitated by interactions between $\beta$-arrestin and AP2 (Shukla et al. 2011). While studies of CASR showed that $\beta$-arrestin can be recruited, this did not enhance receptor internalisation, which only occurred when cells were treated with high concentrations of $\mathrm{Ca}^{2+}{ }_{\mathrm{e}}(10 \mathrm{mM})$ (Lorenz et al. 2007). $\beta$-Arrestin is also now recognised to have another function, as a scaffold protein that facilitates signalling either at the plasma membrane or for some GPCRs, at the endosome (Shukla et al. 2014). This function of $\beta$-arrestin has been recognised for CASR in some studies, providing seemingly contradictory information to that in studies of functional desensitisation. Thus, treatment of cells with dominant-negative forms of $\beta$-arrestin1 or $\beta$-arrestin2, or with siRNA targeting $\beta$-arrestin1 or $\beta$-arrestin2, reduces the pERK and membrane ruffling signals downstream of CASR (Bouschet et al. 2005, Thomsen et al. 2012, Gorvin et al. 2018b). Further studies are required to determine whether the discrepancies within these data sets are due to experimental differences, differences in cell type or if both desensitisation and enhanced signalling occur downstream of CASR, but at different spatial or temporal points.

\section{Regulation of cell surface expression by the secretory pathway and agonist-driven insertional signalling (ADIS)}

The cell surface expression of CASR and mechanisms by which the receptor is synthesised and exported to the plasma membrane are generally well understood. The CASR is synthesised at the endoplasmic reticulum (ER) where it forms homodimers (Pidasheva et al. 2006) and undergoes quality control and immature glycosylation steps prior to progression to the Golgi (Fan et al. 1997). At the Golgi, the CASR undergoes further maturation. This forward trafficking through the secretory pathway involves a number of regulatory proteins that have been well described in previous reviews (Huang et al. 2011, Breitwieser 2013). The core-glycosylated CASR is then retained within pre-plasma membrane compartments (Fan et al. 1997). 
Therefore, CASR is retained intracellularly within two large intracellular reserves: one at the ER and one at pre-plasma membrane compartments (Breitwieser 2012).

The large pool of fully mature CASR plays a unique role in regulation of $\mathrm{Ca}^{2+}{ }_{\mathrm{e}}$. Unlike many GPCRs, the CASR is chronically exposed to its ligand at baseline concentrations, and thus the receptor undergoes very little functional desensitisation (Gama \& Breitwieser 1998). Furthermore, CASR is able to elicit signalling responses for as long as elevated $\mathrm{Ca}^{2+}{ }_{\mathrm{e}}$ is available (Pi et al. 2005, Lorenz et al. 2007, Grant et al. 2011). Experimental studies have sought to explain this apparent paradox and using a combination of total internal reflection fluorescence microscopy (TIRFm) and a construct that allows the simultaneous measurement of CASR insertion within plasma membranes and endocytosis (known as BSEP-CASR), a new model for CASR cell surface expression has emerged (Fig. 4). This model proposes that in the basal state, CASR is only weakly expressed at the plasma membrane, but on exposure to increases in $\mathrm{Ca}^{2+}{ }_{\mathrm{e}}$ there is an increase in anterograde trafficking through the secretory pathway (Grant et al. 2011) (Fig. 4). This increase in the secretory pathway involves both mature CASR located in pre-plasma membrane regions, and newly synthesised CASR from the ER (Grant et al. 2011,
Breitwieser 2013), and at present, the mechanisms that trigger the ADIS events are not fully elucidated. However, studies in which ADIS and CASR signalling were measured simultaneously revealed that elevated $\mathrm{Ca}^{2+}{ }_{\mathrm{i}}$ and the $\mathrm{G}_{\mathrm{q} / 11}$ pathway are likely involved (Grant et al. 2012, Gorvin et al. 2018b). Furthermore, the 14-3-3 proteins, which bind CASR at an Arg-rich site within the C-terminus, limit the release of CASR from the ER, and therefore regulate CASR cell surface expression by reducing the ADISmobilisable pool of the receptor (Grant et al. 2015). The presence of the ADIS system and constitutive endocytosis may also explain some of the inconsistencies between studies of CASR trafficking, as endocytosis of the receptor is balanced by the continual insertion of new CASR from the secretory pathway (Breitwieser 2013). Those studies in which a tagged construct and cell surface labelling (e.g. FLAG) was used in isolation, without also measuring insertion of new CASR within the plasma membrane, may not reflect the physiological state. Similarly, measurement of total cell surface expression of receptor cannot be used as a surrogate for determining the rate of internalisation.

These studies have demonstrated that trafficking of the CASR plays a critical role in receptor signalling and calcium homeostasis. More recent studies, building upon these initial findings, have identified further insights

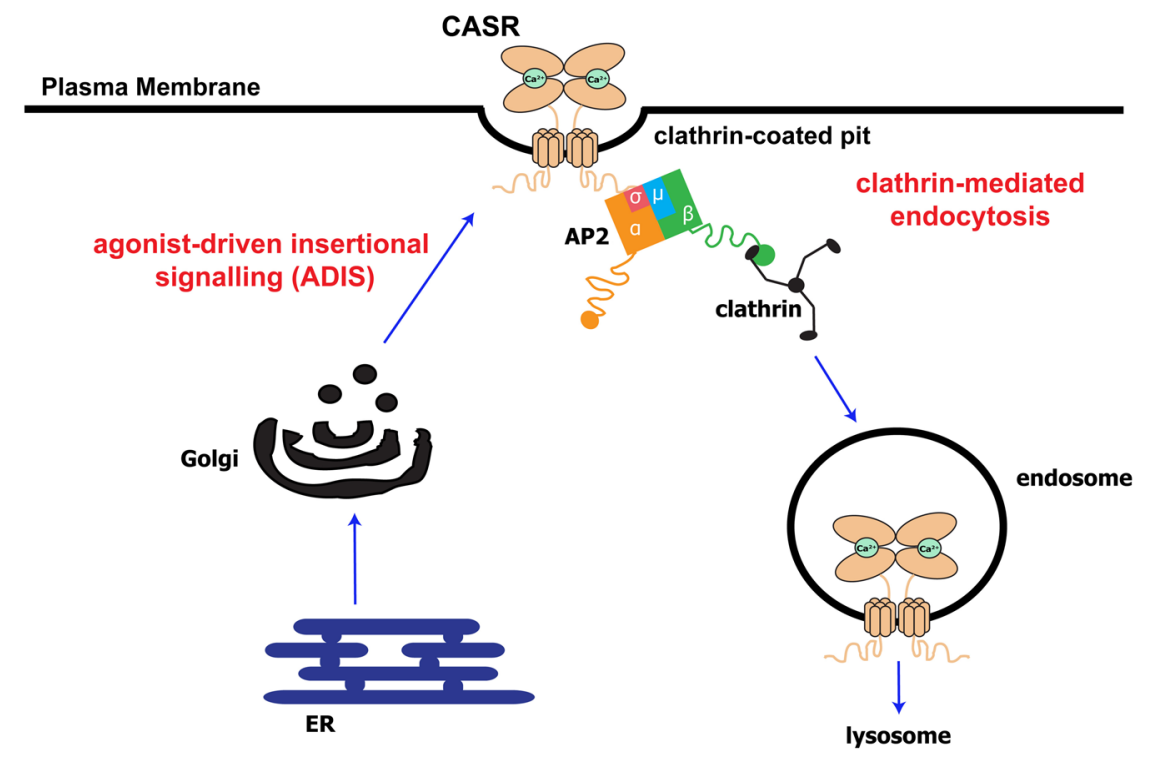

\section{Figure 4}

Mechanisms by which calcium-sensing receptor (CASR) expression is regulated at plasma membranes. Schematic showing trafficking pathways regulating the expression of CASR at the plasma membrane. The CASR is continuously synthesised at the endoplasmic reticulum (ER) and undergoes post-translational modifications at the ER and Golgi, before its export to the plasma membrane surface. In addition to this constitutive anterograde trafficking of the CASR, an additional export pathway for the CASR has been described. This pathway is activated by high $\left[\mathrm{Ca}^{2+}\right]_{\mathrm{e}}$ and has been named the agonist-driven insertional signalling, or ADIS, pathway. Removal of the CASR from the cell surface is regulated by clathrin-mediated endocytosis that requires the heterotetrameric adaptor protein-2 (AP2). AP2 binds directly to transmembrane proteins using its $\mu$-subunit or $\sigma$-subunit. The CASR has a putative dileucine motif within its C-terminus with which it is predicted to bind to AP2 $\sigma$. The $\alpha$-subunit and $\beta$-subunit have large appendages that are important for binding to clathrin coat proteins, plasma membrane phospholipids and endocytic accessory proteins. Once internalised within clathrin-coated vesicles, CASR is targeted to the endosomal-lysosomal system. Experimental evidence suggests that CASR is degraded at the lysosome, and very little, if any, recycling of the receptor occurs. 
into CASR cell surface expression and endocytosis, and recognised further connections between the trafficking and signalling of this receptor.

\section{Regulation of cell surface expression by endocytosis}

The CASR has been described to have two types of internalisation: a constitutive pathway (Grant et al. 2011), and an agonist-driven pathway (Lorenz et al. 2007, Gorvin et al. 2018b). The CASR was shown to internalise using clathrin-mediated endocytosis in early studies (Holstein et al. 2004). In addition, CASR has been described to associate with several proteins that facilitate clustering at the plasma membrane and therefore increase the efficiency of internalisation, or act as scaffolds to enable signalling to occur. One such protein is caveolin-1, with which CASR has been shown to coimmunoprecipitate (Kifor et al. 1998). CASR has been described to be enriched in caveolae structures in parathyroid chief cells and osteosarcoma cells (Kifor et al. 1998, Jung et al. 2005, Sun \& Murphy 2010). CASR-mediated signalling is impaired in cells treated with caveolin-1 targeting siRNA, and it is likely that this signalling function is facilitated by caveolae acting as signalling hubs, allowing the CASR, G-proteins and PKC to cluster together (Kifor et al. 1998, Jung et al. 2005, Sun \& Murphy 2010). However, it is currently unknown whether caveolin facilitates CASR clustering within caveolae structures to enhance signalling, or whether the signalling itself drives this clustering to encourage endocytosis (Breitwieser 2013). Filamin is an actin-binding cytoskeleton protein that is important for protein scaffolding (Hjalm et al. 2001) and may also facilitate clustering that aids in receptor endocytosis. Filamin binds to the CASR C-terminus and increases total cellular content of CASR by preventing its proteosomal degradation (Hjalm et al. 2001), with some studies showing CASR expression is reduced in cells treated with siRNA targeted against filamin. However, other reports show no such changes in CASR expression, and this likely requires further investigation (Huang et al. 2006, Mingione et al. 2017). The net result of filamin A binding to CASR is increased MAPK signalling by the receptor (Hjalm et al. 2001, Pi et al. 2002).

\section{Effect of AP2 $\sigma$ mutations on CASR signalling and trafficking}

Mutations in AP2 $\sigma$ have been demonstrated to cause FHH3, and are associated with impaired CASR-mediated $\mathrm{Ca}^{2+}{ }_{\mathrm{i}}$ signalling (Nesbit et al. 2013b). The AP2 complex is a ubiquitously expressed heterotetrameric protein that plays a fundamental role in the clathrin-mediated endocytosis of transmembrane proteins, such as GPCRs. The two larger subunits, $\alpha$ and $\beta$, have appendages that bind to the clathrin coat proteins, plasma membrane phospholipids and endocytic accessory proteins (e.g. $\beta$-arrestin); while the two smaller subunits, $\mu$ and $\sigma$, bind to endocytic motifs of cargo proteins (Collins et al. 2002, Kelly et al. 2008, Jackson et al. 2010, Kirchhausen et al. 2014) (Fig. 4). The AP2 $\mu$ subunit recognises tyrosine-based motifs and the AP2 $\sigma$ subunit recognises dileucine-based motifs (Haucke \& De Camilli 1999, Kelly et al. 2008) (Fig. 4). FHH3-associated mutations in the AP2 $\sigma$ protein have been reported to affect the Arg15 residue, and structural modelling studies using a published structure of the AP2 complex have shown these missense mutations (to Cys15, His15 and Leu15) likely disrupt interactions with a putative dileucine motif in the CASR C-terminus (Nesbit et al. 2013b), and thus affect CASR endocytosis.

Initially, this hypothesis was tested using an ELISA assay of total CASR at cell surfaces in HEK293 cells stably overexpressing CASR (HEK-CASR), and transiently transfected with AP2 $\sigma$-mutant proteins. This showed that AP2 $\sigma$-mutant expressing cells had increased CASR cell surface expression when compared to AP2 $\sigma$-WT cells following stimulation with $5 \mathrm{mM} \mathrm{Ca}^{2+}{ }_{\mathrm{e}}$ (Nesbit et al. 2013b). Thus, it was concluded that CASR endocytosis is impaired in these cells, resulting in increased total CASR cell surface expression (Nesbit et al. 2013b). More detailed studies characterising the ADIS and endocytosis components of CASR regulation in AP $2 \sigma$ mutant cells using TIRFm and the BSEP-CASR construct showed both ADIS and CASR endocytosis were impaired, resulting in the net effect of an increased total CASR cell surface expression in cells expressing AP2 $\sigma$ mutant protein compared to WT cells (Gorvin et al. 2018b). Additional TIRFm studies focussing on CASR and clathrin demonstrated that CASR and clathrin colocalise at plasma membranes, and that the duration of this colocalisation is prolonged in AP2 $\sigma$ mutant expressing cells (Gorvin et al. 2018b). Furthermore, the vesicles containing both CASR and clathrin in AP2 $\sigma$ mutant cells, when compared to WT cells, were less motile, which is an indication that the vesicles are less likely to result in viable endocytic events (Rappoport \& Simon 2003, Gorvin et al. 2018b). Thus, cells expressing AP2 $\sigma-$ mutant proteins have delayed recruitment of clathrin, and colocalisation with CASR is prolonged, resulting in impaired CASR endocytosis (Gorvin et al. 2018b).

The effect of the FHH3-associated AP2 $\sigma$-mutant proteins on multiple CASR-mediated signalling pathways has been characterised in a number of cellular assays 
in HEK293 cells stable overexpressing AP2 $\sigma$ WT and mutant proteins and lymphoblastoid cell lines derived from blood samples from FHH3 patients with the AP2 $\sigma$ Cys15 mutation (Nesbit et al. 2013b, Gorvin et al. 2018b). These studies confirmed that AP2 $\sigma$ mutations of the Arg15 residue impair $\mathrm{Ca}^{2+}{ }_{\mathrm{i}}$ mobilisation, phosphorylated ERK1/2 (pERK1/2) MAPK signalling, membrane ruffling and suppression of cAMP, and that all of these pathways occur downstream of $\mathrm{G} \alpha_{\mathrm{q} / 11}$ and $\mathrm{G} \alpha_{\mathrm{i} / \mathrm{o}}$ (Nesbit et al. 2013b, Gorvin et al. 2018b). Therefore, these studies have shown that $\mathrm{AP} 2 \sigma$ mutations reduce endocytosis, resulting in increased CASR cell surface expression, but paradoxically decrease CASR-mediated signalling (Gorvin et al. 2018b). To explain this paradox, we hypothesised that CASR may be able to continue signalling from within the cell (i.e. sustained signalling) (Gorvin et al. 2018b). Such sustained signalling has been previously reported for some class A (e.g. $\beta 2$-adrenergic receptor $(\beta 2 \mathrm{AR})$, dopamine receptor D1 (DRD1), thyroid-stimulating hormone receptor, vasopressin receptor 2 (V2R) and luteinizing hormone receptor (LHR)), and class $\mathrm{B}$ (e.g. parathyroid hormone 1 receptor (PTH1R)) GPCRs (Calebiro et al. 2009, Ferrandon et al. 2009, Kotowski et al. 2011, Feinstein et al. 2013, Irannejad et al. 2013, Jean-Alphonse et al. 2014). Thus, in cells with the AP2 $\sigma$ mutation, in which there is impaired endocytosis, the availability of internalised receptors from which sustained signals could emanate would be reduced and thus the net effect would be impaired overall CASR- mediated signalling. To test this hypothesis, a combination of imaging and biochemical analyses, along with chemical inhibitors, were used in HEK-CASR, HEK-AP2 $\sigma$ and CRISPRCas generated $\beta$-arrestin knockout cells to assess CASRmediated MAPK signalling (Gorvin et al. 2018b). To assess sustained signalling, two primary assays were used: (1) assessment of pERK1/2 over $60 \mathrm{~min}$ following treatment of cells with a 5 min pulse of $5 \mathrm{mM} \mathrm{Ca}^{2+}{ }_{\mathrm{e}}$; and (2) analysis of SRE luciferase reporter responses over $12 \mathrm{~h}$, following a 5 min pulse of $5 \mathrm{mM} \mathrm{Ca}^{2+}{ }_{\mathrm{e}}$. Using these methods, MAPKsustained signals were demonstrated in HEK-CASR cells, and evidence for an internal, likely endosomal, source was shown in three ways (Gorvin et al. 2018b) (Fig. 5). First, addition of Dyngo, a chemical inhibitor of dynamin, which is required for vesicle scission during clathrinmediated endocytosis, abolishes sustained signals, whilst rapid plasma membrane-mediated signals remain intact. Loss of this sustained response in Dyngo-treated cells was not due to increased apoptosis or decreased proliferation, and was unaffected by inhibition of CASR protein synthesis as the sustained rise in pERK1/2 was not blocked by tunicamycin, an inhibitor of glycosylation of newly synthesised CASR. Second, sustained signals were reduced in cells expressing a dominant-negative Rab5 protein, which delays maturation of early endosomes and therefore slows clathrin-mediated endocytosis. Third, reduction or loss of these sustained signals was observed in cells expressing AP2 $\sigma$ mutant proteins (Fig. 5).

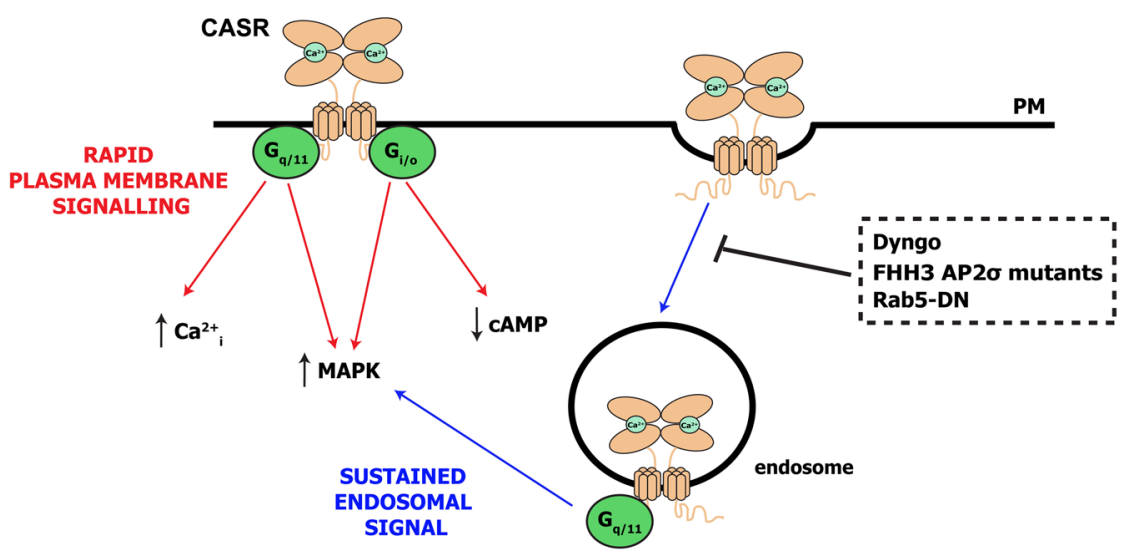

Figure 5

The calcium-sensing receptor (CASR) can activate plasma membrane and endosomal signalling pathways. Schematic diagram showing the signalling pathways that occur downstream of the CASR. As described in Fig. 2, CASR predominantly signals via: the $\mathrm{G}_{\mathrm{q} / 11}$ pathway, leading to activation of the intracellular calcium $\left(\mathrm{Ca}^{2+}{ }_{i}\right)$ and mitogen-activated protein kinase (MAPK) pathways; and the $\mathrm{G}_{\mathrm{i} / \mathrm{o}}$ pathway, leading to activation of MAPK and reductions in the CAMP pathways. These pathways are activated rapidly (within $2-5 \mathrm{~min}$ ), and originate at the plasma membrane. The CASR can also signal from an internal location using a $G_{q / 11}$ pathway. This sustained signal that occurs later than the plasma membrane signal (from $30 \mathrm{~min}$ ) is sensitive to: global clathrin-mediated endocytosis blockade (shown experimentally using Dyngo); inhibition of CASR-mediated internalisation (demonstrated in cells expressing $\mathrm{FHH} 3$-associated $\mathrm{AP} 2 \sigma$ mutants); and maturation of internalised vesicles to the early endosome (demonstrated experimentally using a dominant-negative (DN) form of Rab5). Thus, this sustained signal likely arises within endosomes. 
The G-proteins involved in these sustained signals were also explored as MAPK signalling is a convergence pathway for multiple CASR-mediated signalling pathways (Fig. 2). The ability of the $\mathrm{G} \alpha_{\mathrm{q} / 11}$ and $\mathrm{G} \alpha_{\mathrm{i} / \mathrm{o}}$ pathways to activate CASR sustained signals was investigated using G-protein-specific inhibitors (UBO-QIC and PTx) and the SRE luciferase reporter assay, which showed that inhibition of both $G \alpha_{\mathrm{q} / 11}$ and $\mathrm{G \alpha}_{\mathrm{i} / \mathrm{o}}$ impaired the early, plasma-membrane-mediated CASR signal, while only $G \alpha_{q / 11}$ was important for the later sustained signal. Furthermore, confocal microscopy confirmed that $\mathrm{G \alpha}_{\mathrm{q}}$ and phosphatidylinositol 4,5-bisphosphate $\left(\mathrm{PIP}_{2}\right)$, the lipid hydrolysed by PLC, colocalise with CASR at plasma membranes and a subpopulation of endosomes (Gorvin et al. 2018b). In addition, inhibitors of the PLC-DAG-IP 3 pathway (U73122, GF-109203X and 2-aminoethoxydiphenyl borate (2-APB), which inhibit PLC, PKC and the $\mathrm{IP}_{3}$-receptor, respectively) were shown to reduce sustained pERK1/2 signals, indicating that $\mathrm{G} \alpha_{\mathrm{q} / 11}$ and its signalling pathway are important for CASR-mediated signalling (Gorvin et al. 2018b). Finally, the effects of the $\beta$-arrestin scaffold proteins, which are important for the sustained endosomal signalling of some GPCRs such as V2R and PTH1R (Feinstein et al. 2013, Wehbi et al. 2013), were assessed in HEK-CASR cells with deletion of the $\beta$-arrestin 1 and $\beta$-arrestin 2 genes. In these cells, both pERK and SRE reporter responses were unaffected by deletion of the $\beta$-arrestin proteins (Gorvin et al. 2018b). Thus, the CASR mediates some MAPK signals from endosomes using $\mathrm{G} \alpha_{\mathrm{q}}$ and PLC, but does not require $\beta$-arrestin for this pathway.

\section{Conclusions and important lessons for the future (or unanswered questions)}

Since the cloning of the CASR gene 25 years ago (Brown et al. 1993), many insights have been gained into the role of the CASR in calcium homeostasis, and by studying patients with mutations within this gene, we have learnt much about CASR signalling and trafficking mechanisms. The discovery that CASR can signal from within the cell, most likely from an endosomal source, and that disruption of a specific structural motif can mediate G-protein independent signalling bias, opens up many new avenues of investigation. How do mutations in the CASR affect these endosomal pathways? Can drugs that target the CASR affect these pathways? How are trafficking and signalling of the CASR so intimately linked? Future studies investigating these questions will undoubtedly reveal further complexities into the regulation of CASR, and could provide mechanisms relevant to other GPCRs.

Declaration of interest

The author declares that there is no conflict of interest that could be perceived as prejudicing the impartiality of this review.

\section{Funding}

This research did not receive any specific grant from any funding agency in the public, commercial or not-for-profit sector.

\section{References}

Ballesteros JA, Jensen AD, Liapakis G, Rasmussen SG, Shi L, Gether U \& Javitch JA 2001 Activation of the beta 2-adrenergic receptor involves disruption of an ionic lock between the cytoplasmic ends of transmembrane segments 3 and 6. Journal of Biological Chemistry 276 29171-29177. (https://doi.org/10.1074/jbc.M103747200)

Bouschet T, Martin S \& Henley JM 2005 Receptor-activity-modifying proteins are required for forward trafficking of the calcium-sensing receptor to the plasma membrane. Journal of Cell Science $\mathbf{1 1 8}$ 4709-4720. (https://doi.org/10.1242/jcs.02598)

Breitwieser GE 2012 Minireview: the intimate link between calcium sensing receptor trafficking and signaling: implications for disorders of calcium homeostasis. Molecular Endocrinology 26 1482-1495. (https://doi.org/10.1210/me.2011-1370)

Breitwieser GE 2013 The calcium sensing receptor life cycle: trafficking, cell surface expression, and degradation. Best Practice and Research: Clinical Endocrinology and Metabolism 27 303-313. (https://doi. org/10.1016/j.beem.2013.03.003)

Brown EM 1991 Extracellular Ca2+ sensing, regulation of parathyroid cell function, and role of $\mathrm{Ca} 2+$ and other ions as extracellular (first) messengers. Physiological Reviews 71 371-411. (https://doi. org/10.1152/physrev.1991.71.2.371)

Brown EM, Gamba G, Riccardi D, Lombardi M, Butters R, Kifor O, Sun A, Hediger MA, Lytton J \& Hebert SC 1993 Cloning and characterization of an extracellular $\mathrm{Ca}(2+)$-sensing receptor from bovine parathyroid. Nature 366 575-580. (https://doi. org/10.1038/366575a0)

Calebiro D, Nikolaev VO, Gagliani MC, de Filippis T, Dees C, Tacchetti C, Persani L \& Lohse MJ 2009 Persistent cAMP-signals triggered by internalized G-protein-coupled receptors. PLoS Biology 7 e1000172. (https://doi.org/10.1371/journal.pbio.1000172)

Chang W, Tu C, Cheng Z, Rodriguez L, Chen TH, Gassmann M, Bettler B, Margeta M, Jan LY \& Shoback D 2007 Complex formation with the Type B gamma-aminobutyric acid receptor affects the expression and signal transduction of the extracellular calciumsensing receptor. Studies with HEK-293 cells and neurons. Journal of Biological Chemistry 282 25030-25040. (https://doi.org/10.1074/jbc. M700924200)

Chattopadhyay N \& Brown EM 2006 Role of calcium-sensing receptor in mineral ion metabolism and inherited disorders of calcium-sensing. Molecular Genetics and Metabolism 89 189-202. (https://doi. org/10.1016/j.ymgme.2006.07.003)

Collins BM, McCoy AJ, Kent HM, Evans PR \& Owen DJ 2002 Molecular architecture and functional model of the endocytic AP2 complex. Cell 109 523-535. (https://doi.org/10.1016/S0092-8674(02)00735-3)

Conigrave AD \& Ward DT 2013 Calcium-sensing receptor (CaSR): pharmacological properties and signaling pathways. Best Practice and 
Research: Clinical Endocrinology and Metabolism 27 315-331. (https:// doi.org/10.1016/j.beem.2013.05.010)

Fan G, Goldsmith PK, Collins R, Dunn CK, Krapcho KJ, Rogers KV \& Spiegel AM 1997 N-linked glycosylation of the human Ca2+ receptor is essential for its expression at the cell surface. Endocrinology 138 1916-1922. (https://doi.org/10.1210/endo.138.5.5131)

Feinstein TN, Yui N, Webber MJ, Wehbi VL, Stevenson HP, King JD Jr, Hallows KR, Brown D, Bouley R \& Vilardaga JP 2013 Noncanonical control of vasopressin receptor type 2 signaling by retromer and arrestin. Journal of Biological Chemistry 288 27849-27860. (https:// doi.org/10.1074/jbc.M112.445098)

Ferrandon S, Feinstein TN, Castro M, Wang B, Bouley R, Potts JT, Gardella TJ \& Vilardaga JP 2009 Sustained cyclic AMP production by parathyroid hormone receptor endocytosis. Nature Chemical Biology 5 734-742. (https://doi.org/10.1038/nchembio.206)

Firek AF, Kao PC \& Heath H, 3rd 1991 Plasma intact parathyroid hormone (PTH) and PTH-related peptide in familial benign hypercalcemia: greater responsiveness to endogenous PTH than in primary hyperparathyroidism. Journal of Clinical Endocrinology and Metabolism 72 541-546. (https://doi.org/10.1210/jcem-72-3-541)

Gama L \& Breitwieser GE 1998 A carboxyl-terminal domain controls the cooperativity for extracellular Ca2+ activation of the human calcium sensing receptor. A study with receptor-green fluorescent protein fusions. Journal of Biological Chemistry 273 29712-29718. (https://doi. org/10.1074/jbc.273.45.29712)

Gama L, Wilt SG \& Breitwieser GE 2001 Heterodimerization of calcium sensing receptors with metabotropic glutamate receptors in neurons. Journal of Biological Chemistry 276 39053-39059. (https://doi. org/10.1074/jbc.M105662200)

Geng Y, Mosyak L, Kurinov I, Zuo H, Sturchler E, Cheng TC, Subramanyam P, Brown AP, Brennan SC, Mun HC, et al. 2016 Structural mechanism of ligand activation in human calcium-sensing receptor. Elife 5 e13662. (https://doi.org/10.7554/eLife.13662)

Gorvin CM, Cranston T, Hannan FM, Rust N, Qureshi A, Nesbit MA \& Thakker RV 2016 A G-protein subunit-alpha11 loss-of-function mutation, Thr54Met, causes familial hypocalciuric hypercalcemia type 2 (FHH2). Journal of Bone and Mineral Research 31 1200-1206. (https://doi.org/10.1002/jbmr.2778)

Gorvin CM, Hannan FM, Cranston T, Valta H, Makitie O, SchalinJantti C \& Thakker RV 2017a Cinacalcet rectifies hypercalcemia in a patient with familial hypocalciuric hypercalcemia type 2 (FHH2) caused by a germline loss-of-function Galpha11 mutation. Journal of Bone and Mineral Research 33 32-41. (https://doi.org/10.1002/ jbmr.3241)

Gorvin CM, Hannan FM, Howles SA, Babinsky VN, Piret SE, Rogers A, Freidin AJ, Stewart M, Paudyal A, Hough TA, et al. 2017b Galpha11 mutation in mice causes hypocalcemia rectifiable by calcilytic therapy. JCI Insight 2 e91103. (https://doi.org/10.1172/jci. insight.91103)

Gorvin CM, Babinsky VN, Malinauskas T, Nissen PH, Schou AJ, Hanyaloglu AC, Siebold C, Jones EY, Hannan FM \& Thakker RV $2018 a$ A calcium-sensing receptor mutation causing hypocalcemia disrupts a transmembrane salt bridge to activate $\beta$-arrestin biased signaling. Sci Signal 11 eaan3714. (https;//doi.org/10.1172/10.1126/ scisignal.aan3714)

Gorvin CM, Rogers A, Hastoy B, Tarasov AI, Frost M, Sposini S, Inoue A, Whyte MP, Rorsman P, Hanyaloglu AC, et al. 2018b AP2 $\sigma$ mutations impair calcium-sensing receptor trafficking and signaling revealing an endosomal pathway that spatially directs G-protein selectivity. Cell Reports 22 1054-1066. (https://doi.org/10.1016/j. celrep.2017.12.089)

Grant MP, Stepanchick A, Cavanaugh A \& Breitwieser GE 2011 Agonist-driven maturation and plasma membrane insertion of calcium-sensing receptors dynamically control signal amplitude. Science Signaling 4 ra78. (https://doi.org/10.1126/ scisignal.2002208)
Grant MP, Stepanchick A \& Breitwieser GE 2012 Calcium signaling regulates trafficking of familial hypocalciuric hypercalcemia (FHH) mutants of the calcium sensing receptor. Molecular Endocrinology 26 2081-2091. (https://doi.org/10.1210/me.2012-1232)

Grant MP, Cavanaugh A \& Breitwieser GE 2015 14-3-3 proteins buffer intracellular calcium sensing receptors to constrain signaling. PLoS ONE 10 e0136702. (https://doi.org/10.1371/journal.pone.0136702)

Hannan FM \& Thakker RV 2013 Calcium-sensing receptor (CaSR) mutations and disorders of calcium, electrolyte and water metabolism. Best Practice and Research: Clinical Endocrinology and Metabolism 27 359-371. (https://doi.org/10.1016/j.beem.2013.04.007)

Hannan FM, Nesbit MA, Zhang C, Cranston T, Curley AJ, Harding B, Fratter C, Rust N, Christie PT, Turner JJ, et al. 2012 Identification of 70 calcium-sensing receptor mutations in hyper- and hypo-calcaemic patients: evidence for clustering of extracellular domain mutations at calcium-binding sites. Human Molecular Genetics 21 2768-2778. (https://doi.org/10.1093/hmg/dds105)

Hannan FM, Howles SA, Rogers A, Cranston T, Gorvin CM, Babinsky VN, Reed AA, Thakker CE, Bockenhauer D, Brown RS, et al. 2015 Adaptor protein-2 sigma subunit mutations causing familial hypocalciuric hypercalcaemia type 3 (FHH3) demonstrate genotypephenotype correlations, codon bias and dominant-negative effects. Human Molecular Genetics 24 5079-5092. (https://doi.org/10.1093/ hmg/ddv226)

Haucke V \& De Camilli P 1999 AP-2 recruitment to synaptotagmin stimulated by tyrosine-based endocytic motifs. Science $\mathbf{2 8 5}$ 1268-1271. (https://doi.org/10.1126/science.285.5431.1268)

Hjalm G, MacLeod RJ, Kifor O, Chattopadhyay N \& Brown EM 2001 Filamin-A binds to the carboxyl-terminal tail of the calcium-sensing receptor, an interaction that participates in CaR-mediated activation of mitogen-activated protein kinase. Journal of Biological Chemistry 276 34880-34887. (https://doi.org/10.1074/jbc.M100784200)

Hofer AM \& Brown EM 2003 Extracellular calcium sensing and signalling. Nature Reviews Molecular Cell Biology 4 530-538. (https:// doi.org/10.1038/nrm1154)

Holstein DM, Berg KA, Leeb-Lundberg LM, Olson MS \& Saunders C 2004 Calcium-sensing receptor-mediated ERK1/2 activation requires Galphai2 coupling and dynamin-independent receptor internalization. Journal of Biological Chemistry 279 10060-10069. (https://doi.org/10.1074/jbc.M312039200)

Hu J, Reyes-Cruz G, Chen W, Jacobson KA \& Spiegel AM 2002 Identification of acidic residues in the extracellular loops of the seven-transmembrane domain of the human $\mathrm{Ca} 2+$ receptor critical for response to $\mathrm{Ca} 2+$ and a positive allosteric modulator. Journal of Biological Chemistry 277 46622-46631. (https://doi.org/10.1074/jbc. M207100200)

Hu J, McLarnon SJ, Mora S, Jiang J, Thomas C, Jacobson KA \& Spiegel AM 2005 A region in the seven-transmembrane domain of the human $\mathrm{Ca} 2+$ receptor critical for response to $\mathrm{Ca} 2+$. Journal of Biological Chemistry 280 5113-5120. (https://doi.org/10.1074/jbc. M413403200)

Hu J, Jiang J, Costanzi S, Thomas C, Yang W, Feyen JH, Jacobson KA \& Spiegel AM 2006 A missense mutation in the seven-transmembrane domain of the human $\mathrm{Ca} 2+$ receptor converts a negative allosteric modulator into a positive allosteric modulator. Journal of Biological Chemistry 281 21558-21565. (https://doi.org/10.1074/jbc. M603682200)

Huang C, Wu Z, Hujer KM \& Miller RT 2006 Silencing of filamin A gene expression inhibits Ca2+-sensing receptor signaling. FEBS Letters $\mathbf{5 8 0}$ 1795-1800. (https://doi.org/10.1016/j.febslet.2006.02.035)

Huang Y, Cavanaugh A \& Breitwieser GE 2011 Regulation of stability and trafficking of calcium-sensing receptors by pharmacologic chaperones. Advances in Pharmacology 62 143-173. (https://doi. org/10.1016/B978-0-12-385952-5.00007-5)

Irannejad R, Tomshine JC, Tomshine JR, Chevalier M, Mahoney JP, Steyaert J, Rasmussen SG, Sunahara RK, El-Samad H, Huang B, et al. 
2013 Conformational biosensors reveal GPCR signalling from endosomes. Nature 495 534-538. (https://doi.org/10.1038/ nature12000)

Jackson LP, Kelly BT, McCoy AJ, Gaffry T, James LC, Collins BM, Honing S, Evans PR \& Owen DJ 2010 A large-scale conformational change couples membrane recruitment to cargo binding in the AP2 clathrin adaptor complex. Cell 141 1220-1229. (https://doi. org/10.1016/j.cell.2010.05.006)

Jean-Alphonse F, Bowersox S, Chen S, Beard G, Puthenveedu MA \& Hanyaloglu AC 2014 Spatially restricted G protein-coupled receptor activity via divergent endocytic compartments. Journal of Biological Chemistry 289 3960-3977. (https://doi.org/10.1074/jbc. M113.526350)

Jung SY, Kwak JO, Kim HW, Kim DS, Ryu SD, Ko CB \& Cha SH 2005 Calcium sensing receptor forms complex with and is up-regulated by caveolin-1 in cultured human osteosarcoma (Saos-2) cells. Experimental and Molecular Medicine 37 91-100. (https://doi. org/10.1038/emm.2005.13)

Kelly BT, McCoy AJ, Spate K, Miller SE, Evans PR, Honing S \& Owen DJ 2008 A structural explanation for the binding of endocytic dileucine motifs by the AP2 complex. Nature 456 976-979. (https://doi. org/10.1038/nature07422)

Kifor O, Diaz R, Butters R, Kifor I \& Brown EM 1998 The calciumsensing receptor is localized in caveolin-rich plasma membrane domains of bovine parathyroid cells. Journal of Biological Chemistry 273 21708-21713. (https://doi.org/10.1074/jbc.273.34.21708)

Kifor O, MacLeod RJ, Diaz R, Bai M, Yamaguchi T, Yao T, Kifor I \& Brown EM 2001 Regulation of MAP kinase by calcium-sensing receptor in bovine parathyroid and CaR-transfected HEK293 cells. American Journal of Physiology: Renal Physiology 280 F291-F302. (https://doi.org/10.1152/ajprenal.2001.280.2.F291)

Kirchhausen T, Owen D \& Harrison SC 2014 Molecular structure, function, and dynamics of clathrin-mediated membrane traffic. Cold Spring Harbor Perspectives in Biology 6 a016725. (https://doi. org/10.1101/cshperspect.a016725)

Kotowski SJ, Hopf FW, Seif T, Bonci A \& von Zastrow M 2011 Endocytosis promotes rapid dopaminergic signaling. Neuron $\mathbf{7 1}$ 278-290. (https://doi.org/10.1016/j.neuron.2011.05.036)

Leach K, Wen A, Davey AE, Sexton PM, Conigrave AD \& Christopoulos A 2012 Identification of molecular phenotypes and biased signaling induced by naturally occurring mutations of the human calcium-sensing receptor. Endocrinology 153 4304-4316. (https://doi.org/10.1210/en.2012-1449)

Leach K, Wen A, Cook AE, Sexton PM, Conigrave AD \& Christopoulos A 2013 Impact of clinically relevant mutations on the pharmacoregulation and signaling bias of the calcium-sensing receptor by positive and negative allosteric modulators. Endocrinology 154 1105-1116. (https://doi.org/10.1210/en.2012-1887)

Li D, Opas EE, Tuluc F, Metzger DL, Hou C, Hakonarson H \& Levine MA 2014 Autosomal dominant hypoparathyroidism caused by germline mutation in GNA11: phenotypic and molecular characterization. Journal of Clinical Endocrinology and Metabolism 99 E1774-E1783. (https://doi.org/10.1210/jc.2014-1029)

Lorenz S, Frenzel R, Paschke R, Breitwieser GE \& Miedlich SU 2007 Functional desensitization of the extracellular calcium-sensing receptor is regulated via distinct mechanisms: role of $\mathrm{G}$ proteincoupled receptor kinases, protein kinase $\mathrm{C}$ and beta-arrestins. Endocrinology 148 2398-2404. (https://doi.org/10.1210/en.20061035)

Mannstadt M, Harris M, Bravenboer B, Chitturi S, Dreijerink KM, Lambright DG, Lim ET, Daly MJ, Gabriel S \& Juppner H 2013 Germline mutations affecting Galpha11 in hypoparathyroidism. New England Journal of Medicine 368 2532-2534. (https://doi.org/10.1056/ NEJMc1300278)

Marx SJ 2015 Letter to the editor: distinguishing typical primary hyperparathyroidism from familial hypocalciuric hypercalcemia by using an index of urinary calcium. Journal of Clinical Endocrinology and Metabolism 100 L29-L30. (https://doi.org/10.1210/jc.2014-4221)

Miedlich SU, Gama L, Seuwen K, Wolf RM \& Breitwieser GE 2004 Homology modeling of the transmembrane domain of the human calcium sensing receptor and localization of an allosteric binding site. Journal of Biological Chemistry 279 7254-7263. (https://doi. org/10.1074/jbc.M307191200)

Mingione A, Verdelli C, Ferrero S, Vaira V, Guarnieri V, Scillitani A, Vicentini L, Balza G, Beretta E, Terranegra A, et al. 2017 Filamin A is reduced and contributes to the CASR sensitivity in human parathyroid tumors. Journal of Molecular Endocrinology 58 91-103. (https://doi.org/10.1530/JME-16-0184)

Nesbit MA, Hannan FM, Howles SA, Babinsky VN, Head RA, Cranston T, Rust N, Hobbs MR, Heath H 3rd \& Thakker RV 2013a Mutations affecting G-protein subunit alpha11 in hypercalcemia and hypocalcemia. New England Journal of Medicine 368 2476-2486. (https://doi.org/10.1056/NEJMoa1300253)

Nesbit MA, Hannan FM, Howles SA, Reed AA, Cranston T, Thakker CE, Gregory L, Rimmer AJ, Rust N, Graham U, et al. 2013b Mutations in AP2S1 cause familial hypocalciuric hypercalcemia type 3. Nature Genetics 45 93-97. (https://doi.org/10.1038/ng.2492)

Obermannova B, Banghova K, Sumnik Z, Dvorakova HM, Betka J, Fencl F, Kolouskova S, Cinek O \& Lebl J 2009 Unusually severe phenotype of neonatal primary hyperparathyroidism due to a heterozygous inactivating mutation in the CASR gene. European Journal of Pediatrics 168 569-573. (https://doi.org/10.1007/s00431008-0794-y)

Pearce SH, Trump D, Wooding C, Besser GM, Chew SL, Grant DB, Heath DA, Hughes IA, Paterson CR, Whyte MP, et al. 1995 Calciumsensing receptor mutations in familial benign hypercalcemia and neonatal hyperparathyroidism. Journal of Clinical Investigation 96 2683-2692. (https://doi.org/10.1172/JCI118335)

Pearce SH, Bai M, Quinn SJ, Kifor O, Brown EM \& Thakker RV $1996 a$ Functional characterization of calcium-sensing receptor mutations expressed in human embryonic kidney cells. Journal of Clinical Investigation 98 1860-1866. (https://doi.org/10.1172/JCI118987)

Pearce SH, Williamson C, Kifor O, Bai M, Coulthard MG, Davies M, Lewis-Barned N, McCredie D, Powell H, Kendall-Taylor P, et al. 1996b A familial syndrome of hypocalcemia with hypercalciuria due to mutations in the calcium-sensing receptor. New England Journal of Medicine 335 1115-1122. (https://doi.org/10.1056/ NEJM199610103351505)

Petrel C, Kessler A, Dauban P, Dodd RH, Rognan D \& Ruat M 2004 Positive and negative allosteric modulators of the $\mathrm{Ca} 2+-$ sensing receptor interact within overlapping but not identical binding sites in the transmembrane domain. Journal of Biological Chemistry 279 18990-18997. (https://doi.org/10.1074/jbc.M400724200)

Pi M, Spurney RF, Tu QS, Hinson T \& Quarles LD 2002 Calcium-sensing receptor activation of Rho involves filamin and Rho-guanine nucleotide exchange factor. Endocrinology 143 3830-3838. (https:// doi.org/10.1210/en.2002-220240)

Pi M, Oakley RH, Gesty-Palmer D, Cruickshank RD, Spurney RF, Luttrell LM \& Quarles LD 2005 Beta-arrestin- and G protein receptor kinase-mediated calcium-sensing receptor desensitization. Molecular Endocrinology 19 1078-1087. (https://doi.org/10.1210/me.2004-0450)

Pidasheva S, Grant M, Canaff L, Ercan O, Kumar U \& Hendy GN 2006 Calcium-sensing receptor dimerizes in the endoplasmic reticulum: biochemical and biophysical characterization of CASR mutants retained intracellularly. Human Molecular Genetics 15 2200-2209. (https://doi.org/10.1093/hmg/ddl145)

Piret SE, Gorvin CM, Pagnamenta AT, Howles SA, Cranston T, Rust N, Nesbit MA, Glaser B, Taylor JC, Buchs AE, et al. 2016 Identification of a G-protein subunit-alpha11 gain-of-function mutation, Val340Met, in a family with autosomal dominant hypocalcemia type 2 (ADH2). Journal of Bone and Mineral Research 31 1207-1214. (https://doi.org/10.1002/jbmr.2797) 
Pollak MR, Brown EM, Chou YH, Hebert SC, Marx SJ, Steinmann B, Levi T, Seidman CE \& Seidman JG 1993 Mutations in the human $\mathrm{Ca}(2+)$-sensing receptor gene cause familial hypocalciuric hypercalcemia and neonatal severe hyperparathyroidism. Cell $\mathbf{7 5}$ 1297-1303. (https://doi.org/10.1016/0092-8674(93)90617-Y)

Rappoport JZ \& Simon SM 2003 Real-time analysis of clathrin-mediated endocytosis during cell migration. Journal of Cell Science $\mathbf{1 1 6}$ 847-855. (https://doi.org/10.1242/jcs.00289)

Rasmussen SG, Choi HJ, Rosenbaum DM, Kobilka TS, Thian FS, Edwards PC, Burghammer M, Ratnala VR, Sanishvili R, Fischetti RF, et al. 2007 Crystal structure of the human beta2 adrenergic G-protein-coupled receptor. Nature 450 383-387. (https://doi. org/10.1038/nature06325)

Riccardi D \& Brown EM 2010 Physiology and pathophysiology of the calcium-sensing receptor in the kidney. American Journal of Physiology: Renal Physiology 298 F485-F499. (https://doi.org/10.1152/ ajprenal.00608.2009)

Schrage R, Schmitz AL, Gaffal E, Annala S, Kehraus S, Wenzel D, Bullesbach KM, Bald T, Inoue A, Shinjo Y, et al. 2015 The experimental power of FR900359 to study Gq-regulated biological processes. Nature Communications 6 10156. (https://doi.org/10.1038/ ncomms10156)

Shukla AK, Xiao K \& Lefkowitz RJ 2011 Emerging paradigms of betaarrestin-dependent seven transmembrane receptor signaling. Trends in Biochemical Sciences 36 457-469. (https://doi.org/10.1016/j. tibs.2011.06.003)

Shukla AK, Westfield GH, Xiao K, Reis RI, Huang LY, Tripathi-Shukla P, Qian J, Li S, Blanc A, Oleskie AN, et al. 2014 Visualization of arrestin recruitment by a G-protein-coupled receptor. Nature 512 218-222. (https://doi.org/10.1038/nature13430)

Standfuss J, Edwards PC, D'Antona A, Fransen M, Xie G, Oprian DD \& Schertler GF 2011 The structural basis of agonist-induced activation in constitutively active rhodopsin. Nature 471 656-660. (https://doi. $\operatorname{org} / 10.1038 /$ nature09795)

Sun J \& Murphy E 2010 Calcium-sensing receptor: a sensor and mediator of ischemic preconditioning in the heart. American Journal of Physiology: Heart and Circulatory Physiology 299 H1309-H1317. (https://doi.org/10.1152/ajpheart.00373.2010)

Takasaki J, Saito T, Taniguchi M, Kawasaki T, Moritani Y, Hayashi K \& Kobori M 2004 A novel Galphaq/11-selective inhibitor. Journal of Biological Chemistry 279 47438-47445. (https://doi.org/10.1074/jbc. M408846200)
Thomsen AR, Hvidtfeldt M \& Brauner-Osborne H 2012 Biased agonism of the calcium-sensing receptor. Cell Calcium 51 107-116. (https:// doi.org/10.1016/j.ceca.2011.11.009)

Uckun-Kitapci A, Underwood LE, Zhang J \& Moats-Staats B 2005 A novel mutation $(\mathrm{E} 767 \mathrm{~K})$ in the second extracellular loop of the calcium sensing receptor in a family with autosomal dominant hypocalcemia. American Journal of Medical Genetics Part A 132A 125-129. (https://doi.org/10.1002/ajmg.a.30403)

Vargas-Poussou R, Huang C, Hulin P, Houillier P, Jeunemaitre X, Paillard M, Planelles G, Dechaux M, Miller RT \& Antignac C 2002 Functional characterization of a calcium-sensing receptor mutation in severe autosomal dominant hypocalcemia with a Bartter-like syndrome. Journal of the American Society of Nephrology 13 2259-2266. (https://doi.org/10.1097/01. ASN.0000025781.16723.68)

Volpe A, Guerriero A, Marchetta A, Caramaschi P \& Furlani L 2009 Familial hypocalciuric hypercalcemia revealed by chondrocalcinosis. Joint Bone Spine 76 708-710. (https://doi.org/10.1016/j. jbspin.2009.02.001)

Ward DT, Brown EM \& Harris HW 1998 Disulfide bonds in the extracellular calcium-polyvalent cation-sensing receptor correlate with dimer formation and its response to divalent cations in vitro. Journal of Biological Chemistry 273 14476-14483. (https://doi. org/10.1074/jbc.273.23.14476)

Watanabe S, Fukumoto S, Chang H, Takeuchi Y, Hasegawa Y, Okazaki R, Chikatsu N \& Fujita T 2002 Association between activating mutations of calcium-sensing receptor and Bartter's syndrome. Lancet 360 692-694. (https://doi.org/10.1016/S0140-6736(02)09842-2)

Wehbi VL, Stevenson HP, Feinstein TN, Calero G, Romero G \& Vilardaga JP 2013 Noncanonical GPCR signaling arising from a PTH receptor-arrestin-Gbetagamma complex. PNAS 110 1530-1535. (https://doi.org/10.1073/pnas.1205756110)

Wu H, Wang C, Gregory KJ, Han GW, Cho HP, Xia Y, Niswender CM, Katritch V, Meiler J, Cherezov V, et al. 2014 Structure of a class C GPCR metabotropic glutamate receptor 1 bound to an allosteric modulator. Science 344 58-64. (https://doi.org/10.1126/ science.1249489)

Zhang C, Zhang T, Zou J, Miller CL, Gorkhali R, Yang JY, Schilmiller A, Wang S, Huang K, Brown EM, et al. 2016 Structural basis for regulation of human calcium-sensing receptor by magnesium ions and an unexpected tryptophan derivative co-agonist. Science Advances 2 e1600241. (https://doi.org/10.1126/sciadv.1600241)

Received in final form 16 March 2018

Accepted 29 March 2018

Accepted Preprint published online 29 March 2018 